\title{
NIEDHARDT, Gottfried, RIESENBERGER, Dieter, Lernen aus dem Krieg? Deutsche Nachkriegszeiten 1918 und 1945. Beiträge zur historischen Friedensforschung
}

Jean Solchany

\section{(2) OpenEdition}

\section{Journals}

Édition électronique

URL : http://journals.openedition.org/ifha/2045

DOI : $10.4000 /$ ifha. 2045

ISSN : 2198-8943

Éditeur

IFRA - Institut franco-allemand (sciences historiques et sociales)

Référence électronique

Jean Solchany, « NIEDHARDT, Gottfried, RIESENBERGER, Dieter, Lernen aus dem Krieg? Deutsche Nachkriegszeiten 1918 und 1945. Beiträge zur historischen Friedensforschung », Revue de l'IFHA [En ligne], Date de recension, mis en ligne le 01 janvier 1994, consulté le 22 septembre 2020. URL : http:// journals.openedition.org/ifha/2045 ; DOI : https://doi.org/10.4000/ifha.2045

Ce document a été généré automatiquement le 22 septembre 2020.

(C)IFHA 


\title{
NIEDHARDT, Gottfried,
} RIESENBERGER, Dieter, Lernen aus dem Krieg? Deutsche Nachkriegszeiten 1918 und 1945. Beiträge zur historischen Friedensforschung

\author{
Jean Solchany
}

1 Fruit d'un travail collectif de plusieurs années mené par le cercle de travail sur l'histoire de la paix (Arbeitskreis für Historische Friedensforschung), l'ouvrage traite de l'impact des deux conflits mondiaux sur la société allemande. Des élites militaires et politiques au cinéma, au roman et aux monuments aux morts en passant par les syndicats, le protestantisme, les mouvements pacifistes et les historiens, l'éventail de cette investigation est très large. Le souci constant de comparer les deux avant-guerres permet de souligner l'ampleur particulièrement marquée des bouleversements induits par la Seconde Guerre mondiale.

2 Certes, les continuités sont nombreuses par rapport à l'avant-1939, notamment dans le personnel administratif et militaire: ce n'est qu'au cours des années soixante, par exemple, que le recrutement des officiers supérieurs se diversifie socialement. Les cas $\mathrm{du}$ protestantisme ou des historiens universitaires montrent par ailleurs que bien des pasteurs et des professeurs restent largement tributaires d'une vision du monde traditionnelle typiquement conservatrice. Le contexte de la Guerre Froide permet en outre de brandir avec une ingénuité nouvelle le drapeau de l'anticommunisme, avec la bénédiction de l'allié américain. Le service de renseignements sur l'Union soviétique constitué par la Wehrmacht n'a-t-il pas été maintenu en activité par les autorités d'occupation américaines avant de devenir le Bundesnachrichtendienst en 1956?

3 Mais les analyses nuancées des auteurs soulignent également la portée des mutations induites par l'écroulement de 1945. Au lendemain de 1918, l'imaginaire politique des élites traditionnelles - militaires, hommes politiques, professeurs, pasteurs - n'avait 
pas véritablement été fragilisé par la défaite. Bien au contraire, c'est l'ordre nouveau qui se trouva mis en cause au nom des valeurs fondamentales du conservatisme. $\mathrm{Au}$ lendemain de 1945, le désarroi de l'après-guerre s'est en revanche traduit par une acceptation plus prononcée des valeurs de la démocratie occidentale et par un renoncement définitif à une politique de force fondée sur une vision nationaliste de l'histoire.

Jean SOLCHANY 